RASĀYAN J. Chem.

Vol. 13 | No. 1 |767 - 771| January - March | 2020 ISSN: 0974-1496 | e-ISSN: 0976-0083 | CODEN: RJCABP http://www.rasayanjournal.com http://www.rasayanjournal.co.in

\title{
INFLUENCE OF THE DIFFERENT FORMS OF CRUM RUBBER PARTICLE IN NAO BRAKE PAD MATERIALS
}

\author{
Adnan Ibrahim Shihab \\ ${ }^{1}$ Department of Automotive Technology, Erbil Polytechnic University, Iraq \\ *E-mail: adnan.shihab@epu.edu.iq
}

\begin{abstract}
The objective of this work is to analyze the performance and compare the different forms of waste crum rubber available. The tribological performances of the different sizes of the crum rubber are investigated. The main objective is to develop the non-asbestos organic brake pad with the help of the available waste crum rubber particles. In this present investigation, the brake pad was developed and different proportions of crum rubber are studied in the present investigation without varying the other ingredients. Physical, Mechanical and other frictional properties were examined. Chase Test Rig with IS2742 Standards was used to examine the tribological studies. Primary and Secondary plateaus examination was done by using SEM. The results elucidate that the brake pad developed with the highest rubber content and bigger crum rubber size shows good results due to its composition and morphology. Keywords: Waste Crum Rubber, Chase Test, Tribological Properties, Brake Pad.
\end{abstract}

(C) RASĀYAN. All rights reserved

\section{INTRODUCTION}

The Environmental wastes and the new changes in the regulations in the area of disposal waste have changed the research to find the alternative by using the waste as a byproduct ${ }^{1}$ recent years many researchers have been focusing on the use of the waste available particles. The ultimate objective is to utilize the waste rubber particles is to improve the overall performance of the developed composites and also to reduce the overall cost and usage of the natural resources. Many researchers studied the effect of waste tire rubber particles and concluded that the damping ratio can be considerably improved by adding waste tire rubber particles. Liu et $\mathrm{al}^{3}$ researched and concluded that by adding the rubber particles in the brake pads enhanced the wear performance. Chang et $\mathrm{al}^{4}$ investigated and compared the performance of the two different sizes of the tire rubber and he concluded that the smaller micron-sized rubber particles possess good frictional performance but it decreases the wear rate and the frictional stability. Many researchers have analyzed the performance of the different forms of rubber particles. However, detailed studies concerning the addition of the crum rubber have been least reported. Hence this paper analyses the performance of the different sizes of the crum rubber and all the required braking performances are being analyzed in detail which finally enables to development of non-asbestos, low cost and Eco-friendly brake pads. Liu et $\mathrm{al}^{3}$ emphasized that the addition of rubber wastes as a byproduct enhanced the wear performance. The Previous results show that the rubber particles with different percentages have been studied, This work deals with the study of rubber particles in different proportions. The different brake pad composites with different proportions were studied in this work..$^{4-6}$

\section{EXPERIMENTAL}

The different sizes of crum rubber are used in the present investigation which is procured from Sai Rubber and Tier manufacturers. The selection of the percentage was made based on various experiments by the manufacturer. The average flake size was $400 \mu \mathrm{m}$, having a density of $6.3 \mathrm{~g} / \mathrm{cm}^{3}$. The two different sizes of crum rubber that were used in the present investigation included the sizes of $250 \mu \mathrm{m}$ and $400 \mu \mathrm{m}$. The friction composites were developed in the form of standard brake pads. ${ }^{7,8}$ The formulation possessed 15 parental ingredients namely fibers with additives acrylic fiber, rockwool fiber, steel fiber, hydrated

Rasayan J. Chem., 13(1), 767-771(2020)

http://dx.doi.org/10.31788/RJC.2020.1315542




RASĀYAN J. Chem.

Vol. 13 | No. 1 |767-771| January - March | 2020

lime; binders with additives straight phenolic resin, calcium oxide, friction modifiers, synthetic graphite, molybdenum disulfide $\left(\mathrm{MoS}_{2}\right)$, silicon carbide; fillers (inert and functional) cashew friction dust, vermiculite, barites, mica barium sulphate and remaining 5 weight $\%$ as varying ingredients, which include crum rubber in sizes of 250 and $400 \mu \mathrm{m}$. The composites are designated as CR1 and CR2 based on the varying sizes of the crum rubber which includes $250 \mu \mathrm{m}$ and $400 \mu \mathrm{m}$ respectively. The brake pad development methodology is the same as that of the procedure followed in the previous work. ${ }^{11}$ It has been followed as per the procedure followed by Sai Krishnan Et al. ${ }^{11}$ The density of the developed composite was measured with the help of the Archimedes principle Acetone extraction was used to find the uncured resins percentage. Rockwell hardness tester possessing $\mathrm{K}$ scale having steel indenter of $3.125 \mathrm{~mm}$ diameter with an application of $1500 \mathrm{~N}$ was used to measure hardness. The sample of size $10 \mathrm{~mm} * 10 \mathrm{~mm} * 4 \mathrm{~mm}$ was heated in a hot air oven for 40 minutes at $200 \pm 3^{\circ} \mathrm{C}$. The difference in the thickness was noted for heat swell. The above-said tests were measured as per the IS2742 Part-3. The cold shear strength of the developed pads was measured as per ISO-6312, measured at the room temperature environment. ${ }^{9,10}$ The oil porosity of the developed pads was measured for a sample size of $25 \mathrm{~mm} * 25 \mathrm{~mm}$ as per the JIS D 4418 . Chase test following IS2742-Part-4 standards was used to measure the tribological characteristics of the developed samples.

There are seven cycles in this test namely initial baseline, fade-1, recovery-1, wear, fade-2, recovery-2, and final baseline. The samples of size $25 \mathrm{~mm} * 25 \mathrm{~mm}$ were made in contact with the cast iron drum of $280 \mathrm{~mm}$ diameter. The test procedure is given in Table-2. The typical test graphs are given in Fig.-1. The various properties measured and calculated based on the formulas given in the literature are shown in Fig.-3 ( $a$ and $b$ ). The wear loss percentage of the Chase tested samples were found in terms of weight loss percentage and thickness loss percentage using the digital weighing machine and digital micrometer respectively.

Table-1: Experimental Procedure of the Chase Test as per IS2742-Part-4 Standards

\begin{tabular}{|c|c|c|c|c|c|c|c|c|c|c|}
\hline \multirow[t]{2}{*}{ Cycles } & \multirow{2}{*}{$\begin{array}{l}\text { Speed } \\
(\mathrm{rpm})\end{array}$} & \multicolumn{2}{|c|}{$\begin{array}{c}\text { Temperature } \\
\left({ }^{\circ} \mathrm{C}\right)\end{array}$} & \multirow{2}{*}{$\begin{array}{l}\text { Load } \\
(\mathrm{N})\end{array}$} & \multicolumn{2}{|c|}{ On-time } & \multirow{2}{*}{$\begin{array}{c}\text { Off } \\
\text { time } \\
\text { sec }\end{array}$} & \multirow{2}{*}{$\begin{array}{c}\text { No. of } \\
\text { Applications }\end{array}$} & \multirow{2}{*}{ Heater } & \multirow{2}{*}{ Blower } \\
\hline & & $\min$ & $\max$ & & $\min$ & $\mathrm{sec}$ & & & & \\
\hline Burnish & 308 & - & 93 & 440 & 20 & - & - & 1 & Off & Off \\
\hline $\begin{array}{c}\text { Initial } \\
\text { Baseline }\end{array}$ & 411 & 82 & 104 & 660 & - & 10 & - & 20 & Off & Off \\
\hline Fade-I & 411 & 82 & 289 & 660 & 10 & - & - & 1 & On & Off \\
\hline Recovery-I & 411 & 261 & 93 & 660 & - & 10 & - & 1 & Off & On \\
\hline Wear & 411 & 193 & 204 & 660 & - & 20 & 10 & 100 & Off & Off \\
\hline Fade-II & 411 & 82 & 345 & 660 & 10 & - & - & 1 & On & Off \\
\hline Recovery-II & 411 & 317 & 93 & 660 & - & 10 & - & 1 & Off & On \\
\hline $\begin{array}{c}\text { Final } \\
\text { Baseline }\end{array}$ & 411 & 82 & 104 & 660 & - & 10 & 20 & 20 & Off & Off \\
\hline
\end{tabular}

RESULTS AND DISCUSSION

Physico-chemical and Mechanical Properties of the Developed Brake-pad Composites

The required properties for the performance of the brake pad are calculated and presented in the below table. The outcome obtained is density got decreased and porosity got increased. This is due to the outset of increasing the rubber content. This trend in density was expected as the increment of low dense waste tire rubber content was done by removing an equal amount of high dense brake pad compositions. The main reason for this is due to the agglomeration of waste tire rubber with increased content led to severe structural discontinuities which resulted in increased porosity. As expected, the ash content decreases and acetone extraction increases with increased waste rubber loading because it is organic. As evident from Table-3, the hardness decreased on increasing waste rubber content. This may be attributed to the fact that phenolic resin can provide stronger interface bonding with ingredients, which could become poorer when the waste rubber content reached a higher level, resulting in the decreased stiffness of the composites. 
RASĀYAN J. Chem.

Vol. 13 | No. 1 |767 - 771| January - March | 2020

\section{Tribological Performance Evaluation of the Developed Friction Composites}

Chase test graphs were used to measure the parameters and it is provided below and various parameters calculated are given in Fig.-2. It is concluded that the values of all the friction composites are within the industrial range of 0.3-0.6. The frictional performances of the developed pad which includes a fade coefficient of friction $(\mu \mathrm{F})$, performance coefficient of friction $(\mu \mathrm{P})$ and recovery coefficient of friction $(\mu \mathrm{R})$ were illustrated in Fig. -2 . All the observed values were in the range between 0.25 to $0.40 \mathrm{The} \mu \mathrm{P}$ was in the range between 0.260 to 0.360 while $\mu \mathrm{F}$ prevailed in the range between 0.21 to 0.30 and the recovery friction $\mu \mathrm{R}$ were in the range between 0.31 to 0.35 . Based on the above results it can be concluded that the size of the waste tire rubber increases the friction coefficients $(\mu \mathrm{P}, \mu \mathrm{F}, \mu \mathrm{R})$ decreases and the order is CR2 $>$ CR1. The main reason for this is due to the presence of a significant amount of organic materials attributed to playing a major role in the size and shape of the waste tire rubber. The composite CR2 showed better overall friction performance (uperformance) compared to the other composites.

The crum rubber composites brake pads are developed and their stability coefficient and variability coefficient of the friction composites discussed in Fig.-2. The stability coefficient is examined and analyzed with the ratio of the maximum coefficient of friction and the performance coefficient of friction. For good braking, the performance stability coefficient should be at the higher-end and the variability coefficient should be at the lower end. The wear performance of CR-2 was considerably higher than the CR-1 Composites due to its flake morphology size distribution. The CR-2 was the highest and it had a value of 0.85 whereas the CR-1 had the frictional stability of 0.81 . By this, it can be concluded that the CR-2 has better performance than CR-1. ${ }^{11-14}$

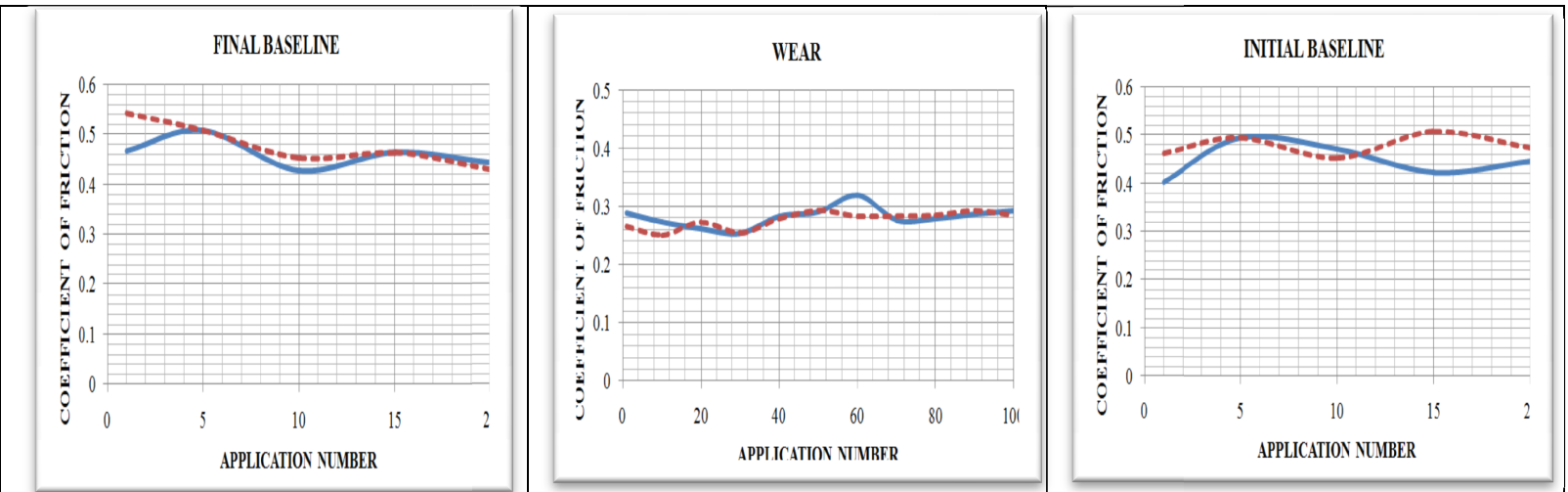

Fig.-1: Chase Test Results for the Developed Composites

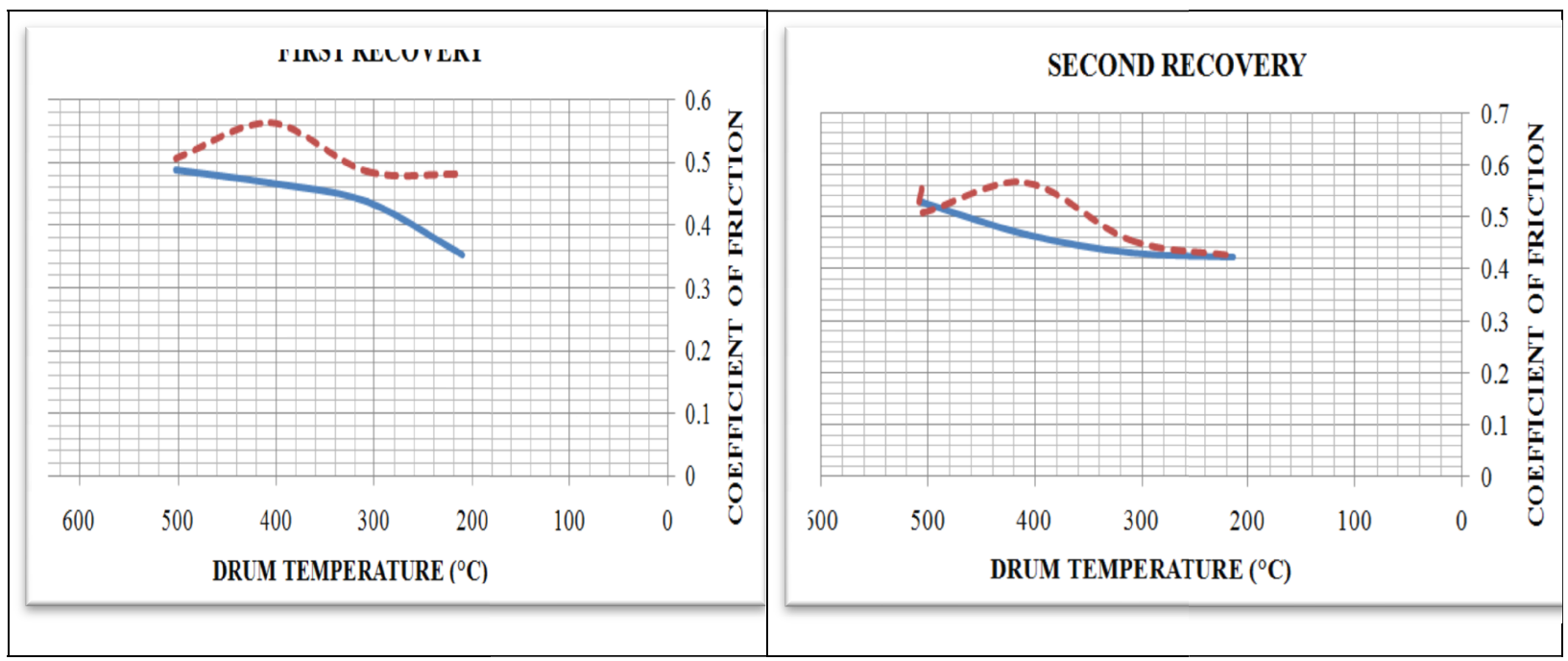


RASĀYAN J. Chem.

Vol. 13 | No. 1 |767- 771| January - March | 2020

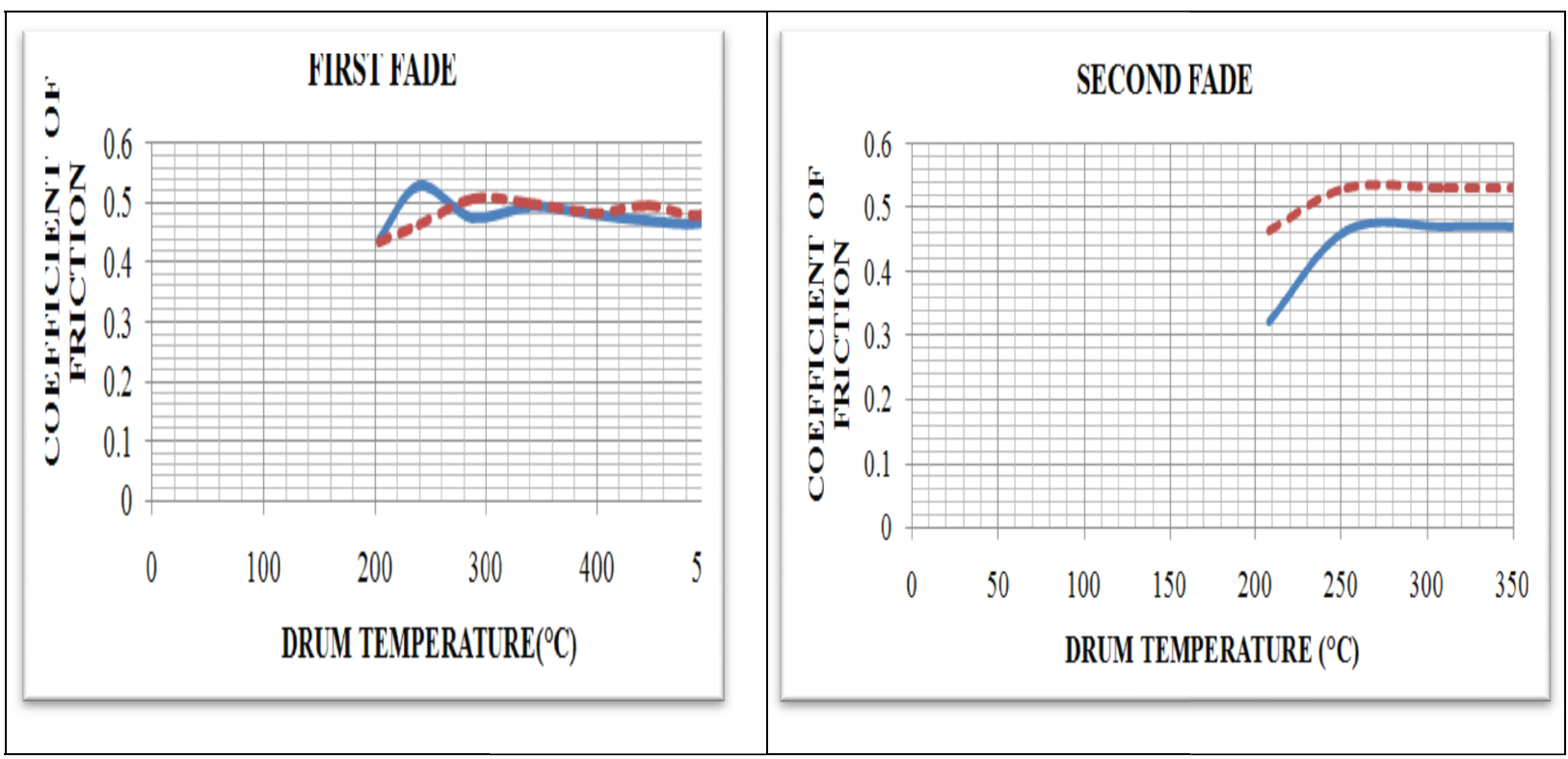

Fig.-2: Chase Test Results for the Developed Composites

Table-2: Physico-Chemical and Mechanical Results

\begin{tabular}{l|l|l}
\hline Properties & CR1 & CR2 \\
\hline Density (g/cm3 ) & 2.11 & 2.07 \\
\hline Porosity (\%) & 5.86 & 6.25 \\
\hline Acetone Extraction & 1.06 & 1.26 \\
\hline Ash Content & 79.77 & 68.65 \\
\hline Hardness & 84.60 & 76.25 \\
\hline
\end{tabular}

\section{REFERENCES}

1. M. R. Sanjay, G. R. Arpitha, L. L. Naik, K. Gopalakrishna and B. Yogesha, Natural Resources, 7(03), 108 (2016).

2. M. R. Sanjay and B. Yogesha, Journal of Industrial Textiles, 47(7), 1830 (2018).

3. Y. Liu, Z. Fan, H. Ma, Y. Tan, J. Qiao, Wear, 261(2), 225(2006), DOI:10.1016/j.wear.2005.10.011

4. H. Chang Brake Friction Materials, in: Q.J. Wang, Y.-W. Chung (Eds.) Encyclopedia of Tribology, Springer US, Boston, MA, 2013, pp. 263-273

5. Y. H. Chang, B. S. Joo, S. M. Lee, H. Jang, Wear, 394-395, 80(2018), DOI:10.1007/978-0-38792897-5_1245

6. M. Prakash and P. Narayanaswamy, Rasayan Journal of Chemistry, 10(2), 442(2017), DOI:10.7324/RJC.2017.1021689

7. A. Alawar, A. M. Hamed, and K. Al-Kaabi, Composites Part B: Engineering, 40(7), 601(2009).

8. M. R. Sanjay, G. R. Arpitha, P. Senthamaraikannan, M. Kathiresan, M. A. Saibalaji and B. Yogesha, Journal of Natural Fibers, 6(4),(2018), DOI: 10.1177/1528083717710713

9. Dinesh Kumar, Ganesh Babu, and G. Sai Krishnan, Polimers, 29(2), 1(2019), DOI:10.1590/01041428.05318

10. G. Sai Krishnan, L. S. Jayakumari, L. Ganesh Babu and G. Suresh, Materials Research Express, 6(8),085109(2019), DOI:10.1088/2053-1591/ab2615

11. G. Sai Krishnan, L. S. Jayakumari, R. Vijay and D. Lenin Singaravelu, Industrial Lubrication and Tribology, 72(1), 66(2019), DOI:10.1108/ILT-12-2018-0441.

12. S. Manoharan, G. Sai Krishnan, L. Ganesh Babu, R. Vijay and D. Lenin Singaravelu, Materials Research Express, 6(10)(2019), DOI:10.1088/2053-1591/ab366f. 
RASĀYAN J. Chem.

Vol. 13 | No. 1 |767-771| January - March | 2020

13. Jeffrey Daniel James D, S. Manoharan, G. Sai Krishnan, S. Arjun, Journal of Natural Fibers,(2018), DOI: $10.1080 / 15440478.2019 .1581119$

14. Jeffrey Daniel James D, G. Sai Krishnan, P.Velmurugan, Materials Research Express, 6(10), 1053469(2019), DOI:10.1088/2053-1591/ab3ae7

15. G. Sai Krishnan, L. Ganesh Babu, P. Kumaran, G. Yoganjaneyulu and Jeganmohan Sudhan Raj, Materials Research Express, 7(1), 015310(2019), DOI:10.1088/2053-1591/ab5d5b

16. G. Sai Krishnan, L. Ganesh Babu, Raghuram Pradhan and S. Kumar, Materials Research Express, 7(1), 2019, DOI:10.1088/2053-1591/ab5af5

[RJC-5542/2019] 